\title{
ABORDAGEM NEUROLINGUÍSTICA DO TEXTO NARRATIVO: UM ENFOQUE TEÓRICO
}

\author{
Gislaine Machado Jerônimo* \\ Lilian Cristine Hübner \\ Pontifícia Universidade Católica do Rio Grande do Sul \\ Porto Alegre, Rio Grande do Sul, Brasil
}

\begin{abstract}
Resumo: O texto narrativo permeia a experiência humana, pois se trata de um texto de uso frequente. No entanto, compreender esse tipo de texto não é uma tarefa simples, uma vez que a compreensão perpassa diferentes níveis, como propõe o Modelo de Processamento Textual, de Kintsch; Van Dijk (1978, 1983), Van Dijk (1992, 2010), Kintsch (1998), Kintsch; Rawson (2013). Sob o prisma da Neurolinguística, trazemos os seguintes questionamentos: como se dá a compreensão do texto narrativo e como os hemisférios cerebrais processam esse tipo de texto? O que estudos experimentais com neuroimagem nos dizem a esse respeito? Quais áreas cerebrais estão imbricadas no processamento da narrativa? A fim de discutir essas questões com base na literatura e oferecer aporte teórico a pesquisas na área, trazemos contribuições da Linguística e da Neurociência sobre a forma como os hemisférios cerebrais cooperam para a representação do texto narrativo.
\end{abstract}

Palavras-chave: Texto narrativo. Niveis de processamento. Compreensão textual. Neurolinguística.

O texto narrativo é um dos mais utilizados na comunicação humana, tanto em termos de compreensão como produção. Sua importância se dá na medida em que ele permeia a nossa experiência. É também um dos primeiros gêneros discursivos a serem adquiridos pela criança e um dos últimos a se perderem no envelhecimento. Tal fato encanta os estudiosos da narrativa e, ao mesmo tempo, os intriga, no sentido de entender quais são os processos que subjazem a essa habilidade linguística (SCHERER; JERÔNIMO; ANSALDO, 2011).

O presente texto vai ao encontro dessa temática e trata dos níveis de representação do texto de gênero narrativo. Nosso olhar está pautado na Neurolinguística, que, com o advento da aplicação das modernas técnicas de neuroimagem nos estudos do processamento de narrativas, tem trazido importantes contribuições a esse respeito. Desse modo, de forma ampla, nos questionamos: o que nos diz a Neuroliguística sobre o processo de compreensão de um texto narrativo? De forma mais específica, como os hemisférios cerebrais processam o texto narrativo? O que estudos experimentais com

\footnotetext{
* Mestre em Linguística pela Pontifícia Universidade Católica do Rio Grande do Sul (PUCRS). Doutoranda em Linguística (PUCRS). Email: gislaine.mjeronimo@gmail.com.

** Doutora em Linguística. Professora Adjunta da Faculdade e do Programa de Pós-graduação em LetrasLinguística da PUCRS. Bolsista de Produtividade em Pesquisa - CNPq. Email: lilian.c.hubner@gmail.com.
} 
neuroimagem nos dizem a esse respeito, a partir de dados de participantes sem acometimento neurológico? Quais áreas cerebrais estariam mais envolvidas com o processamento da narrativa?

Para buscar respostas aos questionamentos apresentados, realizamos uma pesquisa de cunho teórico. O texto está organizado em três seções.

Primeiramente, ao abordar o texto narrativo, ressaltamos o que entendemos por texto, estabelecendo diferença entre texto e discurso, bem como entre gênero e tipo, apresentando o que caracteriza e estrutura da narrativa.

Em um segundo momento, no intuito de abordar os diferentes níveis de compreensão, remetemo-nos aqui ao Modelo de Processamento Textual, de Kintsch; Van Dijk (1978, 1983), Van Dijk (1992, 2010), Kintsch (1998) e Kintsch; Rawson (2013), modelo muito empregado em estudos neurolinguísticos e que propõe os seguintes níveis: microestrutural, macroestrutural e modelo situacional.

Por fim, procurando elucidar a relação entre o processamento da linguagem humana e o funcionamento do cérebro, trazemos uma visão geral de estudos centrados em analisar como os hemisférios cerebrais processam a linguagem/texto. Em seguida mostramos, através de estudos com o uso de técnicas de neuroimagem, a forma como o texto narrativo é processado (compreendido).

A partir dessa discussão, pretendemos pontuar os tópicos recém-elencados e responder aos questionamentos propostos.

\section{TEXTO NARRATIVO E SUA ESTRUTURA}

Os primeiros estudos sobre narrativa surgiram na Grécia antiga, a partir da Poética de Aristóteles (1992), em torno de 335 a.C.. Desde essa época, diversos pesquisadores vêm abordando a estrutura narrativa. No entanto, para uma melhor compreensão do que seja um texto narrativo, é oportuno que, num primeiro momento, estabeleçamos o que entendemos por texto e discurso, bem como por tipo e gênero textual.

Muitos são os aspectos que devem ser considerados para dar conta da definição de texto. Segundo Koch (2008, p. 30):

\footnotetext{
Um texto se constitui enquanto tal no momento em que os parceiros de uma atividade comunicativa global, diante de uma manifestação linguística, pela atuação conjunta de uma complexa rede de fatores de ordem situacional, cognitiva, sociocultural e interacional, são capazes de construir, para ele, determinado sentido.
}

Para Koch (2008), considerando a concepção de texto exposta na citação, o sentido não está no texto, mas é construído a partir dele. Complementando, na perspectiva de Marcuschi (2008, p.72), texto é "um evento comunicativo em que convergem ações linguísticas, sociais e cognitivas". 
Quanto à distinção entre texto e discurso ${ }^{1}$, segundo Marcuschi (2008), esta não deve ser feita de forma muito rígida, visto que a tendência atual é ver um contínuo entre ambos, pois nem todo significado está no âmbito da língua e do sistema (lexicogramatical). O texto necessita de um contexto ${ }^{2}$. O contexto, por sua vez, é algo que não pode ser separado de forma rigorosa do texto e também não pode ser separado do seu contexto discursivo. Trata-se de uma forma de incluir o texto num campo mais vasto das práticas discursivas e de reiterar a articulação entre o plano discursivo e o textual, onde o discurso seria considerado como o objeto do dizer, isto é, a enunciação, e o texto como o objeto de figura - configuração global que pode ter até um único enunciado ou até mesmo um romance inteiro. O que permeia o texto e o discurso, nessa perspectiva, é o gênero - aquele que condiciona a atividade enunciativa.

Segundo Fávero e Koch (2005), as diferentes concepções de texto e discurso ${ }^{3}$ geram confusões, pois ora são empregadas como sinônimas, ora para designar coisas diferentes.

No que tange às concepções de gênero e tipo, Marcuschi (2008) designa tipo como uma espécie de construção teórica definida pela natureza linguística de sua composição, onde entram em cena aspectos lexicais, sintáticos, tempos verbais, relações lógicas e estilo, isto é, seus traços linguísticos predominantes. O tipo caracteriza uma sequência linguística. A rigor, é um modo textual - limitado e sem tendência a aumentar -, que abrange as seguintes categorias: narração, argumentação, exposição, descrição e injunção.

Dessa forma, o que designa um texto do tipo narrativo - que pode ser real ou ficcional - é a estrutura que ele apresenta. A narrativa tem características bem demarcadas, como a sucessão temporal dos acontecimentos, personagens interrelacionados, apresentação de um conflito central e resolução final do conflito estabelecido, que permitem fazer uma projeção aos conhecimentos prévios do leitor (COLOMER; CAMPS, 2002).

O gênero textual ${ }^{4}$, por sua vez, refere-se a textos materializados em situações comunicativas. Ele é um fenômeno histórico, que se vincula à vida cultural e social. São os textos mais encontrados no cotidiano, uma vez que apresentam padrões sociocomunicativos característicos, os quais se manifestam em designações diversas (MARCUSCHI, 2008).

Segundo Marcuschi (2008), os gêneros são formas textuais que se manifestam de forma escrita ou oral. Apresentam características bastante estáveis, pois são histórica e socialmente bem situados. Como exemplo o autor cita: bilhete, carta pessoal, aula expositiva, bula de remédio, piada, cardápio de restaurante, dentre outros.

\footnotetext{
${ }^{1} \mathrm{O}$ presente trabalho não se propõe a aprofundar a discussão entre texto e discurso.

${ }^{2}$ Neste caso, contexto é uma rede de textos que dialogam tanto de modo negociativo como conflituoso.

3 É importante ressaltar que, na literatura das áreas da saúde (incluindo a medicina, a fonoaudiologia) e humanas (incluindo a psicologia), o termo discurso é, em geral, utilizado como sinônimo de texto.

4 Marcuschi (2008) adota a expressão 'gênero textual', em vez de 'gênero discursivo', expressão referida pelo Círculo de Bakhtin.
} 
Mesmo apresentando formas estáveis, os gêneros não são modelos estanques, mas sim formas culturais e cognitivas de ação social. Cabe considerar que os gêneros apresentam uma identidade que, de certa forma, impõe algumas restrições e padronizações.

Nas palavras de Marcuschi (2008, p.176) "todos os textos se realizam em algum gênero e todos os gêneros comportam uma ou mais sequências tipológicas". Ao mesmo tempo, nos gêneros há uma realização de tipos textuais, em que podem estar presentes vários tipos. O tipo é, assim, uma categoria mais ampla, que se concretiza em diferentes gêneros.

O gênero narrativo, enquanto propriedade sociocomunicativa, segundo Scheneuwly e Dols (2004), poderia ser ilustrado a partir dos seguintes exemplos: conto maravilhoso, conto de fadas, fábula, lenda, narrativa de aventura, narrativa de ficção científica, narrativa de enigma, narrativa mítica, conto, crônica, piada, entre outros.

Mais detalhes a respeito das características e estrutura do texto narrativo seguem abaixo.

Como citado anteriormente, dentro dos estudos sobre processamento textual, a forma narrativa tem sido uma das mais investigadas, tanto no contexto de produção como no de compreensão. Ambos os processos são habilidades linguísticas e cognitivas de grande importância para a comunicação, o que explica o interesse de pesquisadores de diferentes áreas no desenvolvimento desse tema (SCHERER; JERÔNIMO; ANSALDO, 2011).

A narrativa ajuda a organizar o pensamento. Ela pode ser uma fonte rica para evocar as lembranças e trazer à tona as memórias, visto que se trata de uma sequência de ideias que é organizada de forma coesa e coerente. É, portanto, inegável a importância de se compreender e produzir narrativas no cotidiano humano. Para esclarecer um pouco suas características e estrutura, nos reportaremos, em especial, ao trabalho de Labov e Waletzky (1967), assim como aos de Adam (1985, 1987, 2008).

Labov e Waletzky (1967), a partir de algumas narrativas orais, coletadas em adultos e entre crianças de diferentes culturas, definem a narrativa como um método de retomada de experiências passadas, comparando sequências verbais de proposições com sequências de eventos anteriores. A narrativa, nessa visão, apresenta duas funções: a de referência e a de avaliação. A primeira refere-se às informações encontradas na própria narrativa, as quais se expressam por meio do lugar, tempo, personagens, eventos (o que, como e onde os fatos ocorrem); enquanto a segunda transmite o motivo pelo qual a narrativa foi contada, isto é, exprime de forma explícita a importância da história para o narrador, bem como os juízos de valor feitos por ele.

Os autores Labov e Waletzky (1967), por entenderem a narrativa dentro de uma visão sociolinguística, centram-se mais na função de avaliação do que na de referência, pois, para eles, é a avaliação que precisa o ponto central da narrativa e coloca o acento sobre os seus eventos principais; secundariamente eles tratam a organização temporal e os eventos objetivos.

Nas palavras de Adam (1984), Labov e Waletzky (1967) percebem que a narrativa apresenta uma dimensão cronológico-sequencial que ordena os elementos um após o 
outro e ao, mesmo tempo, necessita de uma dimensão figuracional, uma espécie de macroestrutura semântica que ordena os elementos narrados. Deste modo, a narrativa apresenta uma superestrutura composta por macroproposições, as quais se agrupam por meio de proposições - sentenças ou frases - menores da narrativa.

A narrativa, de acordo com Labov e Waletzky (1967), é dividida em cinco proposições:

a) Orientação: momento em que se definem as situações de espaço, tempo e características das personagens.

b) Complicação: ocorre após a orientação, por meio de uma ação que visa a modificar o estado inicial da narrativa propriamente dita.

c) Avaliação ou ação: ação: culmina no momento que transforma a nova situação provocada pela complicação; avaliação: momento que indica as reações das personagens.

d) Resolução: estabelecimento de um novo estado, diferente do inicial da história.

e) Conclusão ou moral: conclusão: fechamento da história; moral: consequência da história.

Labov e Waletzky (1967), ao proporem a organização da narrativa, parecem estar mais empenhados em construir uma estrutura que dê conta de reduzi-la a sua forma mais simples e elementar, encontrando, assim, uma estrutura básica que revela sua forma geral. Diferentemente do que propõem esses pesquisadores, para Adam (1985, 2008) o mais importante na sequência narrativa mínima não é a avaliação, mas sim a passagem e a transformação do estado inicial para o final, espaço em que reside o núcleo do processo, isto é, as macroproposições narrativas intermediárias (nó desencadeador - Pn2, re-ação, avaliação - Pn3 e desenlace, resolução - Pn4). Como, na visão de Adam $(1985,2008)$, não há um foco específico no estado inicial, parece não haver necessidade de um estado inicial de equilíbrio. Assim, esse estado pode ser de equilíbrio ou não.

A sequência narrativa elementar em Adam (2008) é bastante semelhante à de Labov e Waletzky (1967), e pode ser representada conforme o seguinte esquema, que também divide a narrativa em cinco proposições $(\mathrm{Pn})$ :

a) Situação inicial (Pn1): momento em que se definem as situações de espaço, tempo e características das personagens.

b) Nó desencadeador (Pn2): ocorre após a situação inicial, por meio de uma ação que visa a modificar o estado inicial da narrativa propriamente dita.

c) Re-ação ou Avaliação (Pn3): re-ação: culmina no momento que transforma a nova situação provocada pela complicação; avaliação: momento que indica as reações das personagens.

d) Desenlace (Pn4): estabelecimento de um novo estado, diferente do inicial da história.

e) Situação final (Pn5): fechamento da história. 
A narrativa apresenta seis importantes componentes para Adam (1987): pelo menos um ator constante; predicados qualitativos (ser) ou funcionais (fazer) definindo um ator em um tempo progressivo; uma sucessão temporal mínima; transformação dos predicados por um processo ou no decorrer dele; uma lógica singular, apresentando causa e efeito dos acontecimentos e um fim sob a forma de moral, avaliação explícita ou a derivar.

Os acontecimentos da narrativa não devem obedecer somente a uma cronologia, na qual há meramente uma descrição de fatos. Tais acontecimentos devem ser significativos para atingir a moral, que deve emergir da história, de forma explícita ou implícita, como característica da superestrutura, evitando que o leitor fique se questionando quanto ao objetivo do texto, isto é, quanto à consequência da história (ADAM, 1987).

Uma sequência de atos orientados não pode constituir uma narrativa, visto que lhe falta o sentido configuracional pragmático, que se dá a partir da passagem da sequencialidade narrativa cronológica dos acontecimentos ao todo nas suas dimensões argumentativa e semântica. Assim, a sequência narrativa é inseparável de uma ordem configuracional (ADAM, 1987).

Neste estudo, optamos por abordar o esquema de sequência narrativa postulado por Labov e Waletzky (1967) e Adam (1984, 1985, 2008), pois ambos utilizam estruturas semelhantes, ao mesmo tempo que enfatizam pontos diferentes. Essa diferença de perspectiva confere grande riqueza ao texto narrativo, pois, ao invés de serem atribuídos à narrativa olhares antagônicos, lançam-se olhares complementares.

Até aqui, trouxemos subsídios teóricos para explicar o que é um texto (narrativo), diferenciando texto de discurso, bem como gênero de tipo textual. Mostramos ainda a forma como se estrutura um texto narrativo. Apresentaremos na próxima seção o Modelo de Processamento Textual proposto por Kintsch e Van Dijk. Trata-se de um dos construtos teóricos mais adotados em pesquisas voltadas à abordagem do texto numa perspectiva neurolinguística, especialmente no que tange aos estudos internacionais.

\section{MODELO DE PROCESSAMENTO TEXTUAL DE KINTSCH E VAN DIJK}

Kintsch e Van Dijk (1978) propõem um modelo de compreensão do discurso, em geral, e do texto escrito, em particular - baseado em dois níveis distintos de representação: o microestrutural e o macroestrutural. Em 1983, acrescentaram um terceiro nível ao modelo: o modelo de situação. Essa distinção surge pela necessidade de se estudar a forma como os indivíduos compreendem e processam o texto ou o discurso como um todo, uma vez que estudos anteriores detinham-se apenas na compreensão da palavra ou da frase (VAN DIJK, 2010). A preocupação dos pesquisadores era a de entender como o leitor ou ouvinte opera estrategicamente com informações de diversos níveis, quer linguístico (morfológicas, sintáticas, semânticas, etc.), quer cognitivo (conhecimento episódico, conhecimento semântico geral, conhecimento sobre textos, etc.), quer contextual (situacional, interacional, pragmático, etc.) (FARIAS, 2000). 
De acordo com Van Dijk (1988), a macroestrutura, ou seja, as ideias principais, compõe a forma global de um texto e define a organização e as relações hierárquicas entre suas partes. A macroestrutura, embora seja uma unidade abstrata, pode, muitas vezes, ser expressa na forma de um resumo da história ou do texto narrado; ela é extraída das proposições ${ }^{5}$ originais do texto (KINTSCH; VAN DIJK, 1983; VAN DIJK, 2010). A macroestrutura estabelece conexões entre proposições relacionadas de forma referencial, causal, lógica ou de outra forma (KINTSCH; RAWSON, 2013). Para que as proposições de um texto ou discurso satisfaçam as condições de coerência devem denotar uma sequência de fatos relatados, tais como causa e efeito, de modo que uma proposição tenha relação com a anterior, bem como com a posterior. As frases apresentadas em um texto são as microestruturas, situadas no nível local da sentença, que se transformam em macroestruturas a partir de regras de mapeamento, como: apagamento, generalização, construção e integração (VAN DIJK, 1988).

a) Apagamento (Deletion) - dada uma sequência de proposições, deve-se eliminar todas as proposições que não constituam pressuposição para as proposições subsequentes. Isto é, devem-se cancelar os detalhes não importantes.

b) Generalização (Generalization) - dada uma sequência de proposições, devese construir uma proposição que contenha conceitos transmitidos na sequência de proposições e substituir, pela proposição constituída, a sequência original.

c) Construção (Construction) - dada uma sequência de proposições, deve-se construir uma proposição que denote o mesmo fato denotado pela união das proposições e substituir a sequência original pela nova proposição.

d) Integração (Integration) - dada uma sequência de proposições, em que uma é integrada à outra, deve-se omitir a informação mais específica, uma vez que ela é uma sequência natural da outra, isto é, evidente. Em: "Eu fumei um cigarro." pode-se omitir a proposição que afirma que eu acendi o cigarro. A integração, do ponto de vista do processamento do discurso, é relevante porque ela organiza a informação que é corretamente relacionada.

É importante ressaltar que, embora as regras de mapeamento de Van Dijk tenham um caráter geral, definindo princípios gerais de informação semântica, nem todos os sujeitos aplicam as regras do mesmo modo. A aplicação dessas regras depende também do tipo de texto em questão (FÁVERO; KOCH, 2005). As autoras - Fávero e Koch (2005) - citam o exemplo de uma história que possui, além de várias estruturas textuais,

\footnotetext{
${ }^{5}$ As proposições são assumidas no modelo de Van Dijk como construções baseadas no significado da palavra, que é ativado da memória semântica, e estruturas sintáticas da oração. O autor assume, grosso modo, que exista "uma relação de um para um entre proposições e oração, isto é, uma oração expressa uma proposição" (VAN DIJK, 2010, p.27). Para definir os termos de uma proposição e relações entre proposições, Van Dijk (2010) segue propostas funcionalistas da linguística, com os formatos de representação de Fillmore (1968) e Givón (1979). A proposição, assim, pode ser descrita como uma estrutura relacional com dois tipos de componentes: um único predicado e um ou mais argumentos (VAN DIJK; KINTSCH, 1983). Cabe ressaltar que predicado e argumento, neste caso, não correspondem à dicotomia sujeito-predicado utilizada na terminologia tradicional. Trata-se de uma estrutura semântica das línguas naturais, em que o predicado é o núcleo oracional (normalmente um verbo), em torno do qual se arranjam os argumentos (sujeitos e complementos) (EVANS; GREEN, 2008).
} 
uma série de sequências com uma estrutura profunda de proposições coerente - uma macroestrutura. Além disso, há uma outra estrutura, que pode ser chamada de superestrutura. Assim, "uma superestrutura, mais do que a forma sintática de uma oração, é descrita em termos de categorias e de regras de formação" (FÁVERO; KOCH, 2005, p. 94). Uma história possui categorias, isto é, superestruturas que não podem ser desprezadas por uma questão de coerência do texto. Citamos a categoria proposta por Adam $(1985,1987,2008)$ para exemplificar a superestrutura da narrativa, que divide uma história em: situação inicial, nó desencadeador, reação ou avaliação, desenlace e situação final. Neste ponto, pode-se destacar a seguinte afirmação de Fávero e Koch (2005, p. 95):

\begin{abstract}
As regras definem em que ordem categorias ocorram, porém a ordem natural é a mencionada acima e a estrutura assim obtida chama-se esquema narrativo ou superestrutura narrativa, que é mais ou menos abstrata, porque não diz nada ainda sobre o conteúdo e expressa-se, também, numa linguagem mais ou menos independente, porque o mesmo esquema pode ser aplicado a uma sequência de cenas.
\end{abstract}

O que as autoras expõem é que a superestrutura está relacionada com os tipos de textos específicos (narração, exposição, argumentação, etc.), obedecendo às características particulares de cada um deles; e que é a superestrutura a responsável pelas categorias gerais das várias formas de discurso. O leitor, por sua vez, saberá qual a estrutura textual quando for contar uma fábula, por exemplo; reconhecerá também essa estrutura no momento da interpretação desse texto.

Em suma, o que Van Dijk e Kintsch destacam é que o significado do texto não está apenas no nível microestrutural, dado a partir de sua coerência local. Pelo contrário, sustenta-se nas ideias principais, o que favorece uma coerência global (VAN DIJK, 1992).

A capacidade de construir um sentido global para o texto sugere a ligação entre a informação nova e o conhecimento prévio do leitor (COLOMER; CAMPS, 2002). Segundo Colomer e Camps (2002), para entender o significado do texto, o leitor tem que elaborar uma interpretação global deste ao longo de sua leitura, o que equivale ao que Van Dijk (1988) chama de construir a macroestrutura mental do texto.

Para Kintsch e Rawson (2013), a compreensão leitora se dá a partir da informação extratextual, que reside no conhecimento de mundo do leitor e da informação implícita no texto. Desse modo, o conteúdo implícito interage com o explícito e os dois se complementam. Segundo os autores, a geração de macroestruturas de textos que sejam de conteúdo familiar passa por um processo automático que necessita de um certo número de inferências, que reduzem ao invés de adicionar conteúdo a um texto.

O leitor, no processo de compreensão de um texto, a partir do input linguístico, cria uma representação semântica mental do texto, que Kintch e Van Dijk denominam texto-base, isto é, um conjunto de proposições que encerram o significado de um texto. O processo de criação do texto-base ocorre paralelamente à ativação - na memória - de um modelo de situação. Em outras palavras, a compreensão do texto não envolve somente a representação de uma base textual na memória, mas, conjuntamente a 
ativação, atualização e outros usos do chamado modelo situacional na memória episódica (VAN DIJK, 2010).

Como recém-mencionado, o modelo de situação é um construto, formado na memória episódica, o qual contém a representação subjetiva do texto; o modelo inclui todo o evento, que lida com as construções pessoais, as inferências e as experiências prévias. Para estabelecer esse modelo de situação, o sujeito utiliza-se de diversos modelos de contexto ${ }^{6}$ para poder recontar um texto: escolha das palavras, estrutura das frases, ênfase, etc.. O conhecimento prévio de leitor é relacionado com os modelos que se encontram na memória episódica (PARENTE et al., 1999).

Esse modelo de situação orienta o leitor na busca de informações relevantes para o estabelecimento da compreensão do texto e pode incluir ainda informações prévias sobre outros textos semelhantes, bem como informações mais gerais sobre a situação em foco. Assim, a compreensão de um texto implica não só a construção de uma representação textual, mas, ao mesmo tempo, do contexto social ao qual se remete (FARIAS, 2000). É o contexto social, requerido ao modelo de situação, que dá um caráter de estudo do discurso à teoria.

O modelo de situação, segundo Kintsch e Van Dijk, é relevante porque limita a quantidade de informações implicadas na compreensão textual; no caso, o leitor não necessita articular todas as informações disponíveis em sua memória, mas apenas aquelas necessárias à leitura do texto, as quais contêm dados importantes para o modelo de situação ativado (KINTSCH; VAN DJIK, 1983; KINTSCH; RAWSON, 2013). Isso quer dizer que quanto mais ricos forem os modelos de situação de que o leitor disponha, isto é, o uso de informação contida no modelo de situação, mais facilmente se dará a compreensão.

Considerando o exposto, é possível, portanto, postular que os conceitos de microestrutura, macroestrutura e modelo de situação permitam melhor entender como se dá o processo de compreensão textual. Não é à toa que o Modelo de Processamento Textual de Kintsch e Van Dijk (1978, 1983), Van Dijk (1992, 2010), Kintsch (1998) e Kintsch e Rawson (2013) seja, de acordo Brandão e Parente (2010), um dos mais utilizados em pesquisas, especialmente aquelas de âmbito internacional (MAR, 2004).

A Neurolinguística traz importantes contribuições sobre a forma como os hemisférios cerebrais processam o texto, trazendo um aporte neurocognitivo aos estudos linguísticos, o que será discutido na próxima seção.

\section{OS HEMISFÉRIOS CEREBRAIS E O PROCESSAMENTO DO TEXTO (NARRATIVO)}

Muita pesquisa ainda é necessária para se obter um melhor entendimento sobre como o cérebro processa a linguagem em um sentido amplo e sobre como os

\footnotetext{
${ }^{6}$ Mais detalhes a respeito do modelo de contexto proposto por Van Djik podem ser obtidos em sua obra Discourse and context: a sociocognitive approach (2008), onde o autor amplia esse conceito. Nessa obra, o modelo de contexto extrapola o nível proposicional e vai em direção a uma representação da experiência, que é análoga a nossa experiência de vida.
} 
hemisférios cerebrais tratam de cada um dos componentes de uma língua: fonológico, morfológico, sintático, semântico e pragmático.

Ao mesmo tempo, a Neurolinguística tem obtido avanços importantes na compreensão desses processos. Esses avanços são possíveis, em especial, por causa das modernas técnicas de neuroimagem. As mais utilizadas são a ressonância magnética funcional - functional magnetic resonance imaging (fMRI) e a tomografia por emissão de pósitron - pósitron emission tomography (PET). Por meio delas é possível examinar a base neural do funcionamento linguístico de indivíduos sem e com lesão cerebral. Considerando a relação linguagem-cérebro, trazemos os seguintes questionamentos: como os hemisférios cerebrais processam o texto narrativo? $\mathrm{O}$ que estudos experimentais com neuroimagem nos dizem a respeito do processamento da narrativa, a partir de dados de participantes sem acometimento neurológico? Quais áreas cerebrais estariam mais envolvidas na compreensão da narrativa?

Os tópicos subsequentes abordam os questionamentos realizados. Primeiramente, trazemos uma visão geral da forma como os hemisférios cerebrais processam a linguagem. Em seguida, analisamos como o texto narrativo é processado.

O hemisfério esquerdo (HE) do cérebro, na segunda metade do século XIX, foi considerado o hemisfério dominante com relação à linguagem, atribuindo-se pouca participação ao hemisfério direito (HD), uma vez que o segundo era visto apenas como subordinado ao primeiro (SPRINGER; DEUTSCH, 1998).

Tal noção de dominância cerebral se deu a partir do estudo de Mark Dax (17711837), um possível pioneiro na evidência de que o HE tem dominância para a linguagem (SPRINGER; DEUTSCH, 1998), bem como Pierre-Paul Broca (1824-1880), que também intitulou o HE como responsável pelas funções da linguagem, após apontar que uma lesão em uma área do lobo frontal do HE (área que foi batizada com seu nome) fazia surgir a afasia ${ }^{7}$ e que lesão semelhante no HD não afetava a linguagem. Em seguida, Karl Wernicke (1848-1905) estabeleceu que problemas de compreensão da linguagem estariam associados a uma área do lobo temporal do HE (área que posteriormente veio a receber seu nome). Wernicke estabeleceu que a afasia poderia decorrer de uma lesão, quer na área de Broca quer na de Wernicke (ROSA, 2010), apontando para uma circuitaria que conectaria duas áreas e seria responsável pela ruptura no processamento entre elas.

Com isso, o HD passa a ter papel marginal em relação ao HE. Mais tarde, em 1876, Jackson sugere que o HD tem papel importante no processamento da percepção visual. Após os estudos de Jackson, em 1876, e depois das duas grandes guerras mundiais, dados com lesados de hemisfério direito (LHD) confirmam a sugestão de Jackson (FONSECA et al., 2006). Grande parte dos estudos sobre o processamento

\footnotetext{
${ }^{7}$ Lesões cerebrais que afetam a linguagem no lado esquerdo do cérebro são, grosso modo, denominadas afasia. Segundo Jakubovicz e Cupello (2005), a afasia é caracterizada por uma desintegração da linguagem que decorre de algum tipo de lesão cerebral. Essa desintegração acarreta uma alteração no conteúdo, na forma e no uso da linguagem e de seus processos cognitivos subjacentes, tais como percepção e memória.
} 
hemisférico tem sido desenvolvida com sujeitos portadores de lesão cerebral, principalmente as decorrentes de acidente vascular encefálico ${ }^{8}$ (AVE).

Essa visão de dominância começou a ser modificada e alguns modelos de processamento hemisférico foram reformulados depois da década de 1950. Bradshaw e Nettleton (1983) defendem a existência de diferenças significativas entre as capacidades de processamento de cada lado do cérebro. O HE é mais associado às habilidades de pensamento linguístico, raciocínio analítico, memória verbal e expressão e recepção da linguagem, enquanto que o HD é associado às funções cognitivas, dentre elas: atenção, percepção e memória visuoespaciais, esquema corporal, inteligência social e emocional, reconhecimento de expressões faciais e habilidade musical (FONSECA et al., 2006).

Com referência às especificidades da linguagem, segundo Fonseca e Parente (2010), as especializações hemisféricas atuam na demarcação de seus componentes estruturais. Assim, a semântica atua em ambos os hemisférios. A fonologia, a morfologia e a sintaxe têm o HE como maior responsável. Já os aspectos comunicativos (discursivos e pragmáticos) ficam em especial a cargo do HD. Assim, o HE responsabiliza-se mais pela organização estrutural e o HD pelo aspecto funcional da linguagem e pelo uso dos elementos extralinguísticos da comunicação. Tal aspecto funcional refere-se às diversas habilidades e situações comunicacionais, pelas quais o HD é o maior responsável.

Segundo Ortiz (2010), a relação mais estreita do HE em termos de linguagem apresenta-se no processamento dos componentes fonético-fonológicos e sintáticos. Porém, quando se trata de processamento semântico, sintático-semântico e discursivo, há uma relação entre ambos os hemisférios cerebrais. Sabendo-se que o processamento do texto narrativo requer, na maioria das vezes, a compreensão de informações literais e não literais, isto é, explícitas e implícitas, e específicas e globais, parece fundamental a participação dos dois hemisférios para que esse processamento ocorra.

Em consonância com grande parte dos estudos mais recentes sobre a especialização hemisférica para o processamento do texto, o HE tende a estar envolvido na coerência mais local e na microestrutura, ao passo que áreas do HD estariam mais implicadas na coerência global e na macroestrutura da mensagem (ST. GEORGE et al., 1999; ROBERTSON et al., 2000; GERNSBACHER; KASCHAK, 2003). Assim, tal distinção processual pode significar uma complementaridade hemisférica (BEEMAN, BOWDEN; GERNSBACHER, 2000) na execução de algumas funções e não somente a dominância de um lado do cérebro em relação ao outro para determinadas habilidades cognitivas, inclusive para as linguísticas.

Os poucos estudos de neuroimagem referidos na literatura no nível do discurso/texto têm indicado que regiões cerebrais similares tendem a ser ativadas em

\footnotetext{
${ }^{8}$ O AVE é a mais frequente das doenças cerebrais encefálicas, podendo ser isquêmico ou hemorrágico. O primeiro é decorrente de processo trombolítico (na arterosclerose, dissecação arterial espontânea ou traumática), embolítico (nas embolias de origem cardíaca) e hemodinâmico (nas situações que causam redução de fluxo sanguíneo cerebral, como em casos de arritmias, choque, parada cardiorrespiratória ou estrangulamento, enquanto o segundo decorre de hemorragia intraparenquimatosa espontânea, hemorragia de aneurisma de vasos cerebrais ou de malformações vasculares (FUKUJIMA, 2010).
} 
todas as investigações, envolvendo principalmente os lobos temporal e frontal. No entanto, falta consenso no que se refere à localização hemisférica, pois alguns estudos apontam para uma maior participação do HE e outros, do HD, quando se faz necessária a integração de proposições de um texto (TOMITCH; JUST; NEWMAN, 2004).

Em favor de uma maior participação do HE na função de integração textual, citamos os trabalhos de Dehaene et al. (1997), Mazoyer et al. (1993), Tomitch (2004) e Loeches (2008). Dehaene et al. (1997), por meio da compreensão auditiva, testaram seus participantes para verificar a compreensão em primeira língua (L1) e segunda língua (L2), por meio da técnica de PET. Seus resultados deram suporte à ideia de que a primeira língua depende grandemente da participação do HE. Em trabalhos posteriores, Dehaene (2009) reitera essa posição. Nas palavras de Tomitch (2004), os resultados encontrados nos estudos de Dehaene mostram que há uma atividade central bilateral na leitura de histórias de uma forma predominante do HE (TOMITCH et al., 2004).

Nessa mesma linha, Mazoyer et al. (1993), através do PET, mencionam que as mesmas áreas cerebrais recrutadas para a compreensão da palavra também são ativadas na compreensão de histórias. São elas: giro temporal medial esquerdo; polos temporais esquerdo e direito; e área pré-frontal superior do lobo frontal esquerdo. Esse estudo contou com três protocolos. No primeiro, os participantes tinham que ouvir atentamente histórias em francês ou em uma língua desconhecida para eles. O objetivo foi o de investigar as áreas cerebrais responsáveis pela continuidade da fala na língua materna. O segundo protocolo foi designado para selecionar, das áreas ativadas, quais eram responsáveis pelo processamento da fala contínua em oposição ao processamento de palavras isoladas. Já no terceiro protocolo, os participantes ouviam histórias que apresentavam distorções; ao invés de ter uma palavra funcional, havia uma pseudopalavra ou uma palavra semanticamente incoerente com as demais.

Loeches (2008), por meio da técnica de fMRI, realiza estudo semelhante ao de St. George e colaboradores (1999) ${ }^{9}$, encontrando resultados divergentes. Loeches (2008) verifica a coerência global do texto através da presença e ausência de título no início da história. Seus participantes deveriam recontar as histórias no escâner. Como resultado, aparece maior ativação do HE nas áreas: precuneus esquerdo e cingulado posterior.

Tomitch et al. (2004), por sua vez, investigam a atividade cerebral durante a execução da tarefa em que os pontos principais da leitura de textos deveriam ser identificados. O estímulo utilizado consiste em doze parágrafos, compostos por ter três orações que deveriam constituir um texto completo. Seus resultados foram congruentes com os de Mazoyer et al. (1993) e Loeches (2008), reiterando uma maior participação do HE na função de integração textual.

Em oposição aos estudos anteriores, St. George et al. (1999) e Robertson et al. (2000) divulgam resultados de estudos sobre a integração de proposições de um texto em que áreas do HD são mais recrutadas.

St. George e colaboradores (1999) apresentaram aos participantes parágrafos sintaticamente bem estruturados, que não podiam ser interpretados a menos que o leitor soubesse de forma independente a que o parágrafo estava se referindo. Tais parágrafos

\footnotetext{
${ }^{9}$ Este estudo será apresentado mais adiante.
} 
estavam precedidos ou não de um título. Nos resultados obtidos por meio da técnica de fMRI não houve impacto sobre o HE se o título era ou não apresentado juntamente com o texto, enquanto que o HD demonstrou maior envolvimento durante a apresentação dos parágrafos sem título. Através desse experimento, pode-se perceber que os parágrafos intitulados recrutaram mais as seguintes áreas do HE: sulcos temporais médio e superior esquerdos, enquanto que os parágrafos sem título ativaram os sulcos temporais médio e superior direito no HD. Esses resultados demonstram maior sensibilidade e participação do HD na tarefa macroestrutural, de compreensão global, que exige inferência do texto; e maior sensibilidade do HE na compreensão dos detalhes, isto é, da microestrutura do texto.

Outro estudo, muito citado em trabalhos principalmente de âmbito internacional, é o de Robertson e colegas (2000). Nesse trabalho, a classe gramatical de artigos foi utilizada para investigar as conexões entre as partes de um texto. Os pesquisadores apresentaram aos leitores dois blocos de sentenças em que cada uma continha um artigo definido ou um artigo indefinido. Houve maior ativação do HD nas sentenças que continham artigo definido do que naquelas com artigo indefinido. As orações com artigo definido foram assumidas como mais coerentes. $\mathrm{O} \mathrm{HE}$ foi mais recrutado no reconhecimento de palavras e processamento sintático na leitura. Concluíram, assim, que a ativação do HD - região frontal - reflete maior dominância nos processos cognitivos de mapear um texto, contrário, portanto, à literatura que atribui maior participação do HE às funções da linguagem.

No intuito de ilustrar os achados da literatura, salientamos esses e ainda outros estudos sobre o assunto, dentre eles, a investigação da atividade neural da compreensão e produção narrativa (ABDULSABUR et al., 2014), o processamento da narrativa e da prosódia na língua de sinais, estudado por Newman et al. (2010); a compreensão da narrativa no bilinguismo, considerando a compreensão da micro, macroestrutura e modelo situacional, por Scherer, Jerônimo e Ansaldo (2011); a compreensão de inferências e Teoria da Mente, pesquisada por Mason e Just (2011); a investigação da arquitetura neural na compreensão oral do discurso narrativo (LILLYWHITE et al., 2010); os mecanismos neurais que dão suporte ao processamento do modelo situacional (YARKONI et al., 2008); por fim, o exame do impacto do contexto no processamento da linguagem, realizado por Xu et al. (2005). Em tais estudos, é possível verificar uma participação efetiva do HD na compreensão global da mensagem.

De acordo com as pesquisas apresentadas no quadro 1 , as principais regiões envolvidas com o processamento do texto narrativo são (ver regiões do quadrol): regiões temporais mediais (principalmente no HD), responsáveis por processos integradores para a coerência global (ST. GEORGE et al., 1999); regiões frontais e temporais do HD envolvendo a integração semântica da informação; regiões parietais posteriores dão suporte para a construção do modelo situacional e regiões frontotemporais, principalmente do HE, dão suporte para a manutenção desse modelo; regiões temporais do HD são ativadas durante a compreensão da macroestrutura e regiões frontais e temporais do HE na compreensão da microestrutura. 
(1)

\section{Quadro 1 - Revisão de alguns estudos neurolinguísticos com neuroimagem sobre 0 processamento do texto (compreensão), por participantes sem lesão cerebral}

\begin{tabular}{|c|c|c|c|}
\hline Autores/técnica & Participantes & $\begin{array}{l}\text { Tipo de processamento do } \\
\text { discurso }\end{array}$ & Regiões cerebrais \\
\hline $\begin{array}{l}\text { Abdul Sabur et al. } \\
\text { (2014) fMRI/PET }\end{array}$ & $\begin{array}{l}16 \text { participantes (11 } \\
\text { mulheres), entre } 20-32 \\
\text { anos, não } \\
\text { especificaram nível } \\
\text { educacional. }\end{array}$ & $\begin{array}{l}\text { Verificar os correlatos } \\
\text { neurais presentes no } \\
\text { processo de compreensão e } \\
\text { produção da narrativa, } \\
\text { considerando o modelo } \\
\text { situacional. }\end{array}$ & $\begin{array}{l}\text { Processo de compreensão: ativação bilateral de } \\
\text { áreas perisilvianas homólogas. Processo de } \\
\text { produção: ativação predominante do hemisfério } \\
\text { esquerdo, áreas executivas e motoras, relacionadas } \\
\text { à formulação da linguagem e articulação. }\end{array}$ \\
\hline $\begin{array}{l}\text { Mason; Just } \\
\text { (2011) fMRI }\end{array}$ & $\begin{array}{l}16 \text { participantes ( } 10 \\
\text { mulheres), todos } \\
\text { alunos de graduação } \\
\text { (não especificam a } \\
\text { idade). }\end{array}$ & $\begin{array}{l}\text { Investigar a ativação cortical } \\
\text { na geração de inferências e } \\
\text { Teoria da Mente (TOM), } \\
\text { através da leitura de trinta } \\
\text { histórias. }\end{array}$ & $\begin{array}{l}\text { Maior demanda na inferência: giro frontal inferior } \\
\text { direito, giro temporal anterior bilateral, giro frontal } \\
\text { superior e medial esquerdo. TOM - junção } \\
\text { temporo-parietal direita. }\end{array}$ \\
\hline $\begin{array}{l}\text { Scherer, } \\
\text { Jerônimo, } \\
\text { Ansaldo (2011) } \\
\text { fNIRS }\end{array}$ & $\begin{array}{l}10 \text { participantes ( } 4 \\
\text { mulheres), entre } 21 \text { e } \\
34 \text { anos de idade, } \\
\text { bilíngues inglês, } \\
\text { francês, escolaridade } \\
\text { entre } 13-20 \text { anos }\end{array}$ & $\begin{array}{l}\text { Investigar o processamento } \\
\text { de narrativas em L2 (macro, } \\
\text { microestrutura e modelo } \\
\text { situacional). }\end{array}$ & $\begin{array}{l}\text { Regiões temporais no HD durante a macroestrutura; } \\
\text { e regiões frontais incluindo Broca e regiões } \\
\text { temporais incluindo a área de Wernicke, no HE na } \\
\text { compreensão da microestrutura. }\end{array}$ \\
\hline $\begin{array}{l}\text { Lillywhite et al. } \\
\text { (2010) fMRI }\end{array}$ & $\begin{array}{l}12 \text { participantes ( } 10 \\
\text { homens), entre } 18-48 \\
\text { anos, cursando nível } \\
\text { superior ou com nível } \\
\text { superior completo. }\end{array}$ & $\begin{array}{l}\text { Investigar a arquitetura } \\
\text { neural da compreensão do } \\
\text { discurso narrativo, } \\
\text { identificando áreas } \\
\text { responsáveis pela repetição } \\
\text { (através de uma história } \\
\text { escutada duas vezes). }\end{array}$ & $\begin{array}{l}\text { Primeira escuta: regiões bilaterais perisilvianas, } \\
\text { incluindo o córtex auditivo. Segunda escuta: a } \\
\text { ativação expande para regiões frontais, parietais e } \\
\text { subcorticais. Na comparação das duas escutas, } \\
\text { houve um significante aumento na ativação do giro } \\
\text { frontal médio bilateralmente e lobo parietal inferior } \\
\text { direito, evidenciando que o HD tem uma importante } \\
\text { participação na compreensão do discurso. }\end{array}$ \\
\hline $\begin{array}{l}\text { Newman et al } \\
\text { (2010) fMRI }\end{array}$ & $\begin{array}{l}14 \text { participantes } \\
(6 \text { mulheres), entre } 18- \\
36 \text { anos, } 3.4 \text { anos de } \\
\text { escolaridade }\end{array}$ & $\begin{array}{l}\text { Explorar o processamento } \\
\text { da narrativa e da prosódia na } \\
\text { língua de sinais. }\end{array}$ & $\begin{array}{l}\text { Ativação na área perisilviana do córtex, bem como } \\
\text { no gânglio basal, regiões mediais frontais e } \\
\text { temporais. O HD teve maior ativação no giro } \\
\text { inferior frontal e sulco temporal superior nas frases } \\
\text { com informações narrativas, envolvendo áreas } \\
\text { semelhantes às do processamento da narrativa na } \\
\text { linguagem falada. }\end{array}$ \\
\hline $\begin{array}{l}\text { Yarkoni; Speer; } \\
\text { Zacks (2008) } \\
\text { fMRI }\end{array}$ & $\begin{array}{l}29 \text { participantes ( } 9 \\
\text { mulheres), entre } 18-32 \\
\text { anos de idade, não } \\
\text { especificam } \\
\text { escolaridade }\end{array}$ & $\begin{array}{l}\text { Explorar mecanismos } \\
\text { neurais suportam o modelo } \\
\text { situacional de } \\
\text { processamento da narrativa } \\
\text { lida. }\end{array}$ & $\begin{array}{l}\text { Regiões parietais posteriores dão suporte a } \\
\text { construção do modelo situacional e regiões fronto- } \\
\text { temporais dão suporte a manutenção desse modelo. }\end{array}$ \\
\hline $\begin{array}{l}\text { Xu et al. (2005) } \\
\text { fMRI }\end{array}$ & $\begin{array}{l}22 \text { participantes } \\
\text { (homens), entre 21-65 } \\
\text { anos de idade, não } \\
\text { especificam } \\
\text { escolaridade. }\end{array}$ & $\begin{array}{l}\text { Mapear a ativação cerebral } \\
\text { no nível da palavra, frase e } \\
\text { narrativa. Examinar o } \\
\text { impacto do contexto no } \\
\text { processamento da } \\
\text { linguagem. }\end{array}$ & $\begin{array}{l}\text { Áreas perisilvianas foram sempre ativadas. } \\
\text { Processamento da frase: opérculo frontal e polos } \\
\text { temporais. Processamento da narrativa: regiões } \\
\text { extrassilvianas em ambos os hemisférios, incluindo } \\
\text { precuneus, frontal medial, e região parieto-temporo- } \\
\text { occipital. O HD foi bastante ativado quando houve } \\
\text { maior complexidade contextual - no nível da } \\
\text { narrativa. }\end{array}$ \\
\hline $\begin{array}{l}\text { Tomitch et al. } \\
\text { (2004) fMRI }\end{array}$ & $\begin{array}{l}8 \text { participantes ( } 2 \\
\text { mulheres), alunos de } \\
\text { graduação, não } \\
\text { especificam idade. }\end{array}$ & $\begin{array}{l}\text { Mapear a ideia principal de } \\
\text { um pequeno texto lido, } \\
\text { apresentada no início ou no } \\
\text { fim. }\end{array}$ & $\begin{array}{l}\text { Ativação bilateral (temporal, frontal inferior, córtex } \\
\text { pré-frontal dorsolateral). }\end{array}$ \\
\hline $\begin{array}{l}\text { Robertson et al. } \\
\text { (2000) fMRI }\end{array}$ & $\begin{array}{l}8 \text { participantes ( } 4 \\
\text { mulheres), não } \\
\text { especificam idade, } \\
\text { nem escolaridade. }\end{array}$ & $\begin{array}{l}\text { Primeiro: compreender o } \\
\text { discurso. } \\
\text { Segundo: ler sentenças e } \\
\text { conectá-las ou não a um } \\
\text { texto. }\end{array}$ & $\begin{array}{l}\text { Primeiro: história com gravuras = mais difusa no } \\
\text { HD: precuneus, cuneus, cingulado posterior, região } \\
\text { parieto-temporo-occipital (bilateralmente); pólos } \\
\text { frontais; tira do córtex do sulco temporal superior } \\
\text { direito ao pólo temporal direito. Regiões do HE } \\
\text { mais associadas com a compreensão do nível mais } \\
\text { superficial do textol. Segundo: sentenças } \\
\text { conectadas = região frontal média e superior no } \\
\text { HD. }\end{array}$ \\
\hline $\begin{array}{l}\text { St. George et al. } \\
\text { (1999) fMRI }\end{array}$ & $\begin{array}{l}10 \text { participantes ( } 5 \\
\text { mulheres), entre } 23-25 \\
\text { anos de idade, não } \\
\text { especificam } \\
\text { escolaridade }\end{array}$ & $\begin{array}{l}\text { Investigar os processos } \\
\text { integradores para a } \\
\text { coerência global na leitura } \\
\text { (histórias } \mathrm{com} / \mathrm{sem} \text { título). }\end{array}$ & $\begin{array}{l}\text { Bilateral: frontal inferior e temporal }(+\mathrm{HD}=\mathrm{sem} \\
\text { título). }\end{array}$ \\
\hline
\end{tabular}


Os estudos apresentados, como já exposto, refletem a escassez de pesquisas com foco nos níveis de representação do texto narrativo (mais especificamente, sobre a microestrutura, macroestrutura e modelo situacional), em concomitância com a utilização de alguma técnica de neuroimagem. Desse modo, por ainda haver pouca publicação na área, algumas limitações se impõem para que se possa realizar algum tipo de generalização, em termos de como o texto é processado no cérebro.

Tais limitações explicam, em parte, os diferentes resultados encontrados nos estudos. As limitações devem-se igualmente às diferentes características das pesquisas. Como observado no Quadro 1, nem todos os estudos apresentam a mesma técnica de neuroimagem. $\mathrm{O}$ número amostral de participantes, a idade e o gênero variam. Há ainda a peculiaridades da língua nativa desses participantes, bem como a peculiaridade do delineamento experimental. Ao mesmo tempo, esses trabalhos se mostram pioneiros na área e, a partir deles, novas hipóteses podem ser levantadas. São necessários, assim, mais estudos que repliquem achados anteriores, em diferentes contextos, porém com equivalentes técnicas de neuroimagem, condições experimentais, características sociodemográficas e culturais dos participantes. Desse modo, poderão ser obtidos dados de diferentes pesquisas que apontem com mais precisão para uma maior ou menor participação de cada um dos hemisférios cerebrais nesse tipo de processamento.

Sobre as conclusões dos estudos abordados, apesar de ainda haver certa divergência nos resultados obtidos, em sua maioria eles indicam que áreas do HD são mais recrutadas na integração de proposições de um texto (macroestrutura) e no processamento de inferências globais (modelo situacional) do que áreas do HE. Já na compreensão da estrutura de superfície, a microestrutura, parece haver um consenso de que áreas do HE recebem mais ativação.

É importante ressaltar que, embora os estudos aqui apresentados tragam evidências de que os dois hemisférios do cérebro processam as informações textuais de forma diferente, ao mesmo tempo as evidências indicam que ambos trocam informações e são cruciais para o entendimento dos diferentes níveis do texto. Esse processo complementar dos hemisférios é necessário para compreender-se a complexidade do texto. Tais resultados sugerem, assim, uma complementaridade hemisférica, no que diz respeito à questão do processamento da narrativa.

Ressalta-se ainda que, neste artigo, a ênfase recaiu sobre o texto narrativo. No entanto, reconhece-se que a discussão, quando se trata da representação do texto no cérebro, é muito mais ampla e se estende a outros tipos e gêneros textuais.

\section{CONSIDERAÇÕES FINAIS}

A proposta do presente artigo foi trazer um enfoque teórico, de cunho neurolinguístico, sobre o processamento do texto narrativo. Em um primeiro momento, alguns conceitos foram apresentados, incluindo a concepção de texto. Elucidamos igualmente a forma como se estrutura um texto narrativo. Em um segundo momento, abordamos o Modelo de Processamento Textual, de Kintsch e Van Dijk (1978, 1983), Van Dijk (1992, 2010), Kintsch (1998) e Kintsch e Rawson (2013). E, em seguida, 
fizemos referência a e discutimos alguns estudos experimentais sobre o processamento do texto narrativo e o funcionamento do cérebro.

Trouxemos alguns questionamentos iniciais, os quais são retomados nesse momento. O primeiro deles refere-se à abordagem da Neurolinguística ao processo de compreensão do texto narrativo. Vale relembrar que o texto, como exposto anteriormente, não é o detentor do sentido, mas o sentido é construído a partir dele, visto que se trata de um evento comunicativo para o qual irão convergir ações linguísticas, sociais e cognitivas. Compreender um texto, desse modo, não é uma tarefa simples ou fácil, principalmente porque há diferentes níveis de processamento textual. Compreender, então, na abordagem neurolinguística aqui trazida, seria acessar e processar efetivamente diferentes níveis do texto.

O Modelo de Kintsch e Van Dijk nos parece bastante adequado na avaliação dos diferentes níveis de representação do texto, no caso da narrativa. Com base nesse modelo é possível estabelecer uma compreensão que vai desde um nível mais superficial, microestrutural, pautado no texto, perpassando um nível intermediário, macroestrutural - capaz de sinalizar as ideias principais do texto, até chegar a um nível mais complexo. Esse último nível, o modelo situacional, abrange o nível inferencial global, para o qual o leitor/ouvinte recruta seu conhecimento prévio a fim de suprir as lacunas deixadas pelo texto.

A forma como os hemisférios cerebrais processam esses níveis de representação, bem como as principais áreas cerebrais envolvidas em tal processo, foram os tópicos abordados nos questionamentos subsequentes. A Neurolinguística, por sua vez, traz importantes evidências - a partir de uma interface entre a Linguística e as Neurociências - e nos ajuda a entender como é possível se estabelecer a relação entre cérebro e linguagem, no sentido de esclarecer como o cérebro realiza o processamento dos três níveis textuais elencados (microestrutura, macroestrutura e modelo situacional). A partir dos resultados dos estudos empíricos aqui abordados, embora alguns deles apresentem certas divergências, considerando sua maioria é possível verificar que áreas do HD parecem estar mais envolvidas com a macroestrutura e com o modelo situacional do que áreas do HE; enquanto que áreas do HE parecem ser mais recrutadas nas tarefas que envolvem a microestrutura textual. Desse modo, parece haver uma complementaridade hemisférica, uma vez que os hemisférios cerebrais trabalham em consonância para uma representação efetiva do texto - no caso de nossa análise, o narrativo.

Como a área é ainda bastante incipiente na comparação com outras áreas da Linguística, algumas limitações se impõem. Há poucos estudos que investigam a relação entre o cérebro e o processamento textual, por meio de técnicas de neuroimagem. Desse modo, a literatura não dispõe de muitos dados. Outrossim, os estudos encontrados abarcam diferentes técnicas, populações e delineamentos teóricometodológicos, dificultando, assim, generalizações. Ao mesmo tempo, tais estudos apresentam certas convergências nos resultados. Apontam, assim, para o desafio de novas propostas de investigação.

Considerando o exposto, é, portanto, possível afirmar que é de grande valia a contribuição da Neurolinguística às suas duas áreas de interesse (a Neurociência e a Linguística), bem como à comunidade científica, em uma troca e complementação de saberes, apontando cada vez mais para novos horizontes de pesquisa. 
ABDULSABUR, N.; XU, Y.; LIU, S.; CHOW, H.; BAXTER, M.; CARSON, J.; BRAUN, A. Neural correlates and network connectivity underlying narrative production and comprehension: a combined study. Cortex, v. 57, p. 107-127, 2014.

ARISTÓTELES. Poética. Tradução de E. de Souza. São Paulo: Ars Poética, 1992.

ADAM, J. Le texte narratif. Paris: Nathan, 1985.

Types de séquences textuelles élémentaires. Tradução de Alexânia Rippol et al., 1992. In:

Pratiques, n. 56, 1987.

A linguística textual: introdução à análise textual dos discursos. São Paulo: Cortez, 2008.

BEEMAN, M.; BOWDEN, E.; GERNSBACHER, M. Right and left hemisphere cooperation for drawing predictive and coherence inferences during normal story comprehension. Brain and Language, v. 71, p. 310-336, 2000.

BRADSHAW J, L.; NETTLETON N, C. Humam cerebral asymmetry. New Jersey: Prentice-Hall, 1983.

BRANDÃO, L; PARENTE, M. A. Compreensão e produção do discurso oral em portadores da doença de Alzheimer. In: ORTIZ, K.Z (Org.) Distúrbios neurológicos adquiridos: linguagem e cognição. São Paulo: Manole, 2010. p. 336-359.

COLOMER, T.; CAMPS, A. Ensinar a ler-ensinar a compreender. Porto Alegre: Artmed, 2002.

CRINION, J.; PRICE, C. Right anterior superior temporal activation predicts auditory sentence comprehension following aphasic stroke. Brain, v.128, p. 2858-2871. 2005.

DEHAENE, S. DUPOUX, E.; MEHLER, J.; COHEN, L. PAULESU, E.; PERANI, D.; MOORTELE, PF.; LEHÉRICY, S.; LE BILHAN, D. Anatomical variability in the cortical representation of first and second language. NeuroReport, v. 8, n. 17, p. 3809-3815, 1997. Group, 2009.

Reading in the brain: the science and evolution of a human invention. Nova York: Penguin EVANS, V.; GREEN, M. Cognitive linguistics: an introduction. Edinburg: Edinburg University Press, 2008.

FARIAS, W.S. Compreensão e resumos de textos: alguns aspectos teóricos e experimentais. Rev. De Letras, v. 1, n. 22, jan./dez. 2000.

FÁVERO, L. L.; KOCH, I. G. Linguística textual: introdução. São Paulo: Cortez, 2005.

FILLMORE, C. The case for case. In: Bach and Harms (Ed.): Universals in Linguistic Theory. New York: Holt, Rinehart, and Winston, 1968, p. 1-88.

FONSECA, R.P.; PARENTE, M.A.M.P.; Relação entre linguagem e hemisfério direito. In: ORTIZ, K.Z (Org.) Distúrbios neurológicos adquiridos: linguagem e cognição. São Paulo: Manole, 2010. p. 136-157.

FONSECA, R. P.; FERREIRA, G. D.; LIEDTKE, F. V; MÜLLER, J. L.; SARMENTO, T. F.;

PARENTE, M. A. Alterações cognitivas, comunicativas e emocionais após lesão hemisférica direita: em busca de uma caracterização da síndrome do hemisfério direito. Psicologia USP, v.7, n.4,p. 241-262, 2006.

FUKUJIMA, M. M. Acidente cerebral vascular. In: ORTIZ, K. Z (Org.) Distúrbios neurológicos adquiridos: linguagem e cognição. São Paulo: Manole, 2010. p. 34-46.

GERNSBACHER, M. A.; KASCHAK, M. P. Neuroimaging studies of language production and comprehension. Annual Review of Psychology, v. 54, p. 91-114, 2003.

GIVÓN, T. On understanding grammar. New York: Academic Press, 1979.

JAKUBOVICZ, R.; CUPELLO, R. Introdução à afasia: Elementos para o diagnóstico e terapia. Rio de Janeiro: Revinter, 2005.

KINTSCH, W. Comprehension: a paradigm for cognition. New York: Cambridge University Press, 1998.

KINTSCH, W.; RAWSON, K. Compreensão. In: SNOWLING, M.; HULME. (Orgs.) A ciência da leitura. Porto Alegre: Penso, 2013.

KINTSCH, W.; Van DIJK, T.A. Toward a model of text comprehension and production. Psychological Review, v. 85, n. 5, p. 363-394, 1978.

KOCH, I.G. O texto e a construção dos sentidos. São Paulo: Contexto, 2008. 
LABOV, W.; WALETZKY, J. Narrative analysis: oral versions of personal experience. In: HELM, J. Essays on the verbal and visual arts. Washington: University of Washington Press, 1967. p. 12-44.

LILLYWHITE, L.; SALING, M.; DEMUTSKA, A.; MASTERTON, R.; FARQUHARSON, S.; JACKSON, G. The neural architecture of discourse compression. Neuropsychologia, v. 48, p. 873-879, 2010.

LOECHES, M.; CASADO, P.; HERNÁNDEZ-TAMAMES, J.; ÁLVAREZ-LINERA, A. Brain activation in discourse comprehension: a 3t fMRI study. Neuroimage, v. 41, p. 614-622, 2008.

MAR, R.A. The neuropsychology of narrative: story comprehension, story production, and their interrelation. Neuropsychologia, v. 42, p. 1414-1434, 2004.

MARCUSCHI, L. A. Produção textual, análise de gêneros e compreensão. São Paulo: Parábola Editorial, 2008.

MASON, R. A.; JUST, M. A. Differentiable cortical networks for inferences concerning people's intentions versus physical causality. Hum Brain Mapp, v. 32, p. 313-329, 2011.

MAZOYER, B. M.; TZOURIO, N.; FRANK, V.; SYROTA, A.; MARAYAMA, N.; LEVRIER, O.; SALAMON, G.; DEHAENE, S.; COHEN, L.; MEHLER, J. The cortical representation of speech. Journal of Cognitive Neuroscience, v. 5, n. 4, p. 467-479, 1993.

NEWMAN, A. J., SUPALLA,T., HAUSER, P. C., NEWPORT, E. L.; BAVELIER, D. Prosodic and narrative processing in american sign language: an fMRI study. Neuroimage, v. 52, p. 669-676, 2010. ORTIZ, K. Z. Terapia nos distúrbios compreensivos. In: ORTIZ, K. Z (Org.) Distúrbios neurológicos adquiridos: linguagem e cognição. São Paulo: Manole, 2010. p. 110-135.

PARENTE, M. A.; CAPUANO, A.; NESPOULOUS, J. L. Ativação de modelos mentais no recontar de histórias por idosos. Psicologia: reflexão e crítica, v. 12, n.1, 1999.

ROBERTSON, D. A.; GERNSBACHER, M. A.; GUIDOTTI, S. J.; ROBERTSON, R. R. W.; IRWIN, W.; MOCK, B.J.; CAMPANA, M. E. Functional neuroanatomy of the cognitive process of mapping during discourse comprehension. Psychol. Sci, v.11, p. 255-260, 2000.

ROSA, M. C. Introdução à (bio) linguística: linguagem e mente. São Paulo: Contexto, 2010.

SCHENEUWLY, B.; DOLZ, J. Gêneros orais e escritos na escola. Tradução e organização Roxane Rojo e Gláis Sales Cordeiro. Campinas, SP: Mercado das Letras, 2004.

SCHERER, L. A Neurolinguística: delimitação do campo de estudos, desafios e perspectivas futuras. In: ENCONTRO DO CÍRCULO DE ESTUDOS LINGUÍSTICOS DO SUL (CELSUL), 9., 2010, Tubarão, SC. RAUEN, F. J. (Org.). Anais do ... Tubarão: Ed. da Unisul, 2010. p. 1-8. Disponível em: $<$ http://www.celsul.org.br/Encontros/09/artigos/Lilian_Scherer.pdf $>$.

SCHERER, L.; JERÔNIMO, G.; ANSALDO, A. O processamento de narrativas em segunda língua: um estudo com fNIRS. In: Bilinguismo/aprendizagem de L2 e processos cognitivos. Porto Alegre: Organon, 2011, p. 291-308.

SPRINGER, S. P.; DEUTSCH G. Cérebro esquerdo, cérebro direito. 2. ed. São Paulo: Summus, 1998.

St. GEORGE, M.; KUTAS, M.; MARTINEZ, A.; SERENO, M. I. Semantic integration in reading: engagement of the right hemisphere during discourse processing. Brain, v. 122, p. 1317-1325, 1999.

TOMITCH, L M.; JUST, M.; NEWMAN, S. A neuroimagem funcional na investigação do processo de leitura. In: RODRIGUES, C.; TOMITCH, L. e colaboradores. Linguagem e Cérebro Humano: contribuições multidisciplinares. Porto Alegre: Artmed, 2004. p.167-173.

VAN DIJK, A. Cognição: discurso e interação. São Paulo: Contexto, 2010.

Modelos na memória - o papel das representações da situação no processamento do discurso. In: Discurso, cognição e leitura. São Paulo: Contexto, p. 158-181, 1988.

Discourse and the denial of racism. Discourse \& Society, v.3, n.1, p. 87-118, 1992.

VAN DIJK, T. A.; KINTSCH, W. Strategies of discourse comprehension. San Diego, California: Academic Press, 1983.

XU, J.; KEMENY, S.; PARK, P.; FRATTALI, C.; BRAUN, A. Language in context: emergent features of word, sentence, and narrative comprehension. Neuroimage, v. 25, p. 1002-1015, 2005.

YARKONI, T.; SPEER, N.; ZACKS, J. Neural substrates of narrative comprehension and memory. Neuroimage, v.1, n. 32, 2008.

Recebido em: 16/09/13. Aprovado em: 29/06/14. 
Title: A neurolinguistic approach to the narrative text: a theoretical perspective Authors: Gislaine Machado Jerônimo; Lilian Cristine Hübner

Abstract: The narrative text permeates human experience. However, narrative understanding is not a simple task, since its comprehension goes through different levels, as proposed by Kintsch; Van Dijk (1978, 1983), Van Dijk (1992, 2010), Kintsch (1998), Kintsch; Rawson (2013), in The Model of Text Processing. From the perspective of Neurolinguistics, we bring the following questions: How narrative text is processed by the cerebral hemispheres? What do experimental neuroimaging studies tell us about it? Which brain areas are embedded in the processing of narrative? In order to discuss these issues based on the literature, and to offer theoretical background for research in this field, we bring contributions from Linguistics and Neurosciences about how the cerebral hemispheres cooperate to process the narrative text.

Keywords: Narrative text. Levels of processing. Textual comprehension. Neurolinguistics.

Título: Abordaje neurolingüistico del texto narrativo: un enfoque teórico

Autores: Gislaine Machado Jerônimo; Lilian Cristine Hübner

Resumen: El texto narrativo permea la experiencia humana, pues se trata de un género de uso frecuente. Sin embargo, comprender ese tipo de texto no es tarea simples, una vez que la comprensión cruza diferentes niveles, como propone el Modelo de Procesamiento Textual de Kintsch y Van Dijk (1978, 1983); Van Dijk (1992, 2010); Kintsch (1998); Kintsch y Rawson (2013). Bajo el prisma de la Neurolingüística, tracemos los siguientes cuestionamientos: ¿cómo ocurre la comprensión del texto narrativo y como los hemisferios cerebrales procesan ese tipo de texto? ¿Qué estudios experimentales con neuroimagen dicen a ese respeto? ¿Cuáles áreas cerebrales están imbricadas en el procesamiento de la narrativa? Para discutir esas cuestiones basado en la literatura y ofrecer aporte teórico para investigaciones en esa área, traemos contribuciones de la Lingüística y de la Neurociencia sobre la forma como los hemisferios cerebrales cooperan para la representación del texto narrativo.

Palabras-clave: Texto narrativo. Niveles de procesamiento. Comprensión textual. Neurolingüística. 